\title{
Atmospheric Solids Analysis Probe with Mass Spectrometry for Chlorpyrifos and Chlorpyrifos-Oxon Determination in Apples
}

\author{
Mirjana R. Cvijović, ${ }^{1, \star}$ Valerio Di Marco, ${ }^{2}$ Srboljub J. Stanković, ${ }^{3}$ Zoran P. Nedić, ${ }^{4}$ \\ Ljubinka G. Joksović ${ }^{5}$ and Nevena R. Mihailović ${ }^{5}$ \\ ${ }^{1}$ Faculty of Medicine, Institute for Microbiology and Immunology, University of Belgrade, Dr Subotića 1, \\ 11000 Belgrade, Serbia \\ ${ }^{2}$ Dipartimento di Scienze Chimiche, University of Padova, Via Marzolo 1, 35131 Padova, Italy \\ ${ }^{3}$ Department of Radiation and Environmental Protection, Vinča Institute of Nuclear Sciences, University of Belgrade, \\ Mike Petrovića 12-14, 11000 Belgrade, Serbia \\ ${ }^{4}$ Faculty of Physical Chemistry, University of Belgrade, Studentski trg 12-16, 11000 Belgrade, Serbia \\ ${ }^{5}$ Faculty of Science, Department of Chemistry, University of Kragujevac, Radoja Domanovića 12, 34000 Kragujevac, Serbia \\ *Corresponding author: E-mail: mirjanacvijovic6@gmail.com; \\ Phone/fax: +381113643366
}

Received: 05-15-2018

\begin{abstract}
Chlorpyrifos (CPS) is a toxic pesticide present in several pesticide formulations, with low degradability by natural processes. The degradation leads to the toxic metabolite chlorpyrifos-oxon (CPO). The analytical techniques used for the CPS and CPO analysis, like UPLC-PDA and GC-MS, are accurate but also expensive and time consuming, and they need sample pretreatment. In the search of a more rapid and simple analytical procedure, atmospheric solids analysis probe with mass spectrometry (ASAP-MS) was optimized for the determination of CPS and CPO in apples (Malus domestica „Idared"). The identification of the analytes was based on protonated ion and isotopic pattern, while the quantification was based on peak intensities. The obtained results were confirmed by re-validated UPLC-PDA and GC-MS techniques. CPS and CPO concentrations determined by ASAP-MS and UPLC-PDA showed moderate discrepancies (on average by 10-20\%), thus demonstrating that ASAP-MS can be a semiquantitative tool for the quantification of these compounds. As additional goal of this work, the efficiency of a gamma irradiation treatment to remove CPS and CPO from apples was tested by analyzing their content before and after the irradiation: $89-99 \%$ of CPS and CPO were degraded with doses of 3.5-3.8 kGy and 66-72 $\mathrm{h}$ of irradiation per sample. Identical degradation results were obtained by UPLC-PDA and ASAP-MS, indicating that the latter technique is well suitable to rapidly check pesticide degradation in apples.
\end{abstract}

Keywords: GC-MS; UPLC-PDA; ASAP-MS; gamma irradiation

\section{Introduction}

Chlorpyrifos (O,O-diethyl-O-3,5,6-trichloro-2-pyridylphosphorothioate, CPS, Figure 1) is an organophosphorous insecticide used in agriculture formulations and in the military field. It is a very persistent (resistant to degradation) and non-volatile compound at room temperature. CPS may be detected in fruit, vegetables, water, soil, and body fluids, even months to years after its application.
This occurs especially after unprofessional application of agricultural formulations, like EC (emulsifiable concentrate) and EW (emulsion in water). EC contains $30-50 \%$ of active substance, organic solvents (such as high-boiling mineral oils, 40-60\%), and emulsifiers, whereas EW contains active substances (about 30\%), emulsifier (15\%), antifreeze (10\%), antifoam, thickener, biocide, stabilizer, buffer, and water. There are also other formulations based on this pesticide. ${ }^{1-3}$ 
The degradation process of CPS leads to the formation of chlorpyrifos-oxon (O,O-diethyl-O-3,5,6-trichloro2-pyridylphosphate, $\mathrm{CPO}$ ) and 3,5,6-trichloro-2-pyridinol (TCP). The formation of $\mathrm{CPO}$ (Figure 1) occurs in animal liver, where a phosphorus-sulfur bond of CPS is replaced by a phosphorus-oxygen bond. ${ }^{4,5}$

TCP is non-toxic, but CPS and CPO are very toxic to humans and cause tens of thousands of deaths per year worldwide because of many reasons: type of pesticide application, short waiting period between treatments, higher doses than allowed, and high toxicity. Both CPS and CPO can cause chemical injury leading to serious damages of human hepatocytes (cells of main liver parenchyma), immune, cognitive, and reproductive systems, in the gastrointestinal tract, and to the hormonal status. The most affected patients are children, elderly, and occupationally exposed people. ${ }^{6} \mathrm{~K}$. Choi et al. and J. Choi et al. demonstrated that CPO inhibits the esterase in human liver. ${ }^{7,8} \mathrm{In}$ case of highly intoxicated liver, metabolic paths change (due to enzyme inhibition) and carcinoma can appear in humans (colorectal carcinoma, liver, lung). ${ }^{9}$ It is known that hepatocytes in humans with polymorphisms do not have the ability to metabolize, detoxify, and inactivate exogenous compounds such as insecticides and drugs. ${ }^{10}$ Thus, both European Commission (EU) and U.S. Environmental Protection Agency (EPA) restricted the use of CPS and are planning to forbid it. The CPS and CPO concentrations in different matrices (food, water, agricultural formulation, blood, urine) should be monitored continuously. ${ }^{11}$

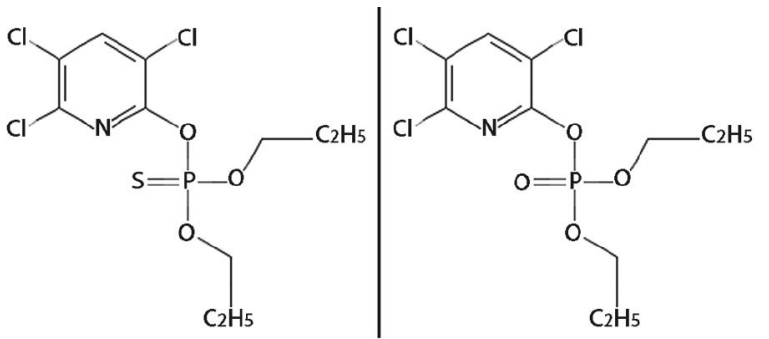

Figure 1. $O, O$-diethyl- $O-3,5,6$-trichloro-2-pyridylphosphorothioate (CPS, left) and $O, O$-diethyl- $O-3,5,6$-trichloro-2-pyridylphosphate $(\mathrm{CPO}$, right)

CPS and CPO concentrations in food and other matrices are most often monitored by chromatographic techniques like high pressure liquid chromatography with photodiode detection (UPLC(HPLC)-PDA), liquid chromatography - mass spectrometry (LC-MS), liquid chromatography - tandem mass spectrometry (LC-MS/MS) ${ }^{12}$, gas chromatography with mass spectrometric detector (GC-MS), gas chromatography with nitrogen phosphorus thermoionic detector (GC-NPD), gas chromatography with flame ionization detector (GC-FID), ${ }^{13,14} 2 \mathrm{D}$-chromatography with simultaneous analysis by two GC columns (GC×GC-FPD) ${ }^{15}$ Other, less used techniques are spectro- scopic ones like infrared spectroscopy (IR), Fourier transform with infrared spectroscopy (FTIR), and attenuated total reflection - Fourier transform with infrared spectroscopy (ATR-FTIR). ${ }^{16}$ Almost all of these techniques are highly expensive, and they require toxic solvents and long time for validation and sample preparation. These techniques are also not suitable to rapidly check the presence or absence of CPS and CPO in food or other matrices.

Atmospheric solids analysis probe with mass spectrometry (ASAP-MS) represents a possible alternative method for the analysis of such analytes. ${ }^{17}$ ASAP-MS utilizes heated nitrogen to vaporize the sample and corona discharge to ionize it. This technique is capable of ionizing low polarity compounds, such as CPS and CPO, not amenable to electrospray (ESI), to atmospheric pressure photoionization (APPI), or to atmospheric pressure chemical ionization (APCI), and it is possible to analyze samples via direct introduction at atmospheric pressure, thus shortening the analysis time and simplifying the procedure. In this paper, therefore, an ASAP-MS method was optimized for the rapid and simple determination of CPS and CPO in plant origin food, such as apples. The obtained results were confirmed by values obtained through standard sample preparation methods (extractions) and chromatographic techniques, i.e. gas chromatography with mass spectrometric detection (GC-MS) and reverse-phase ultra-high performance liquid chromatography with photodiode array detector (RP UPLC-PDA), re-validated for these purposes.

Furthermore, as natural processes (sun, air, microbiological) are not effective enough in real time for the removal of CPS from food, forced processes like chemical (acid and base hydrolysis, oxidation by $\mathrm{H}_{2} \mathrm{O}_{2}$ ) or physical (gamma irradiation) are necessary for the removal of this pesticide or its conversion into nontoxic compound such as TCP. Therefore, another goal of this work was to evaluate if a gamma irradiation treatment is able to efficiently remove CPS and CPO from apples treated by EC and EW formulations. Analytical measurements were performed with both RP UPLC-PDA and ASAP-MS.

\section{Experimental}

\section{1. Materials}

The reference materials for the analysis of CPS $(98.0 \pm 1.0 \%)$ and CPO $(98.0 \pm 1.0 \%)$ were purchased from Dr Ehrenstorfer GmbH (Augsburg, Germany). Multiresidue standard mix with CPS in acetonitrile, Pestanal mix 101 with 20 pesticides and CPS (50 ng/ $\mu \mathrm{L}, 99.0 \pm 0.5 \%$ ) was purchased from Dr Ehrenstorfer GmbH (Augsburg, Germany). The $30 \% \mathrm{H}_{2} \mathrm{O}_{2}$ solution was purchased from MerckCo (Germany). Radar EC and Radar EW, plant protection formulations (active substance CPS $300 \mathrm{~g} / \mathrm{L}$ ), were purchased from Galenika, Phitopharmacia (Belgrade, Serbia). Apples "Idared" were received from domestic pro- 
duction and bought in supermarkets. Methanol, acetonitrile, hexane, petroleum ether, acetone (HPLC grade) were purchased from J. T. Baker (Netherlands). Dichloromethane (HPLC grade) was purchased from Across Organic (New York, USA). Formic acid (98\%) was obtained from J. T. Baker (Netherlands). Glacial acetic acid (99.8\%, HPLC grade) was a Fisher Chemicals (United Kingdom) product. Deionized water was prepared by Purite Select Fusion System. Multi-walled carbon nanotubes (MWCNT) were a Sigma Aldrich product. QuEChERS kit was composed of two extraction mixtures: a mixture of $1.5 \mathrm{~g} \mathrm{CH}_{3} \mathrm{COONa}$ and $6 \mathrm{~g} \mathrm{MgSO}_{4}$, and a PSA sorbent. Cartriges used for analytes separation were Oasis ${ }^{\circledR}$ HLB (hydrophilic-lipophilic balance) from Waters (Milford, MA, USA).

\section{2. Solutions}

Standard stock solutions of CPS and CPO were prepared by dissolving $10 \mathrm{mg}$ of CPS and $5 \mathrm{mg}$ of CPO in $1000 \mu \mathrm{L}$ of methanol (or dichloromethane, depending on the instrumental technique used), and then put in a volumetric Eppendorf tube. The stock solutions were diluted in hexane or in deionized water ( $\mathrm{pH}$ 6.8) to prepare the desired concentrations for the calibration curves for GC-MS or UPLC-PDA, respectively.

EW and EC formulations stock solutions were prepared by dissolving $100 \mu \mathrm{L}$ of formulation in a $10 \mathrm{~mL}$ volumetric flask with dichloromethane (or in methanol/water mixture $1: 3, v / v)$, at a concentration of $3000 \mathrm{mg} / \mathrm{L}$ calculated on active component, and stored at $-18^{\circ} \mathrm{C}$ when not in use.

\section{3. Instrumentations and Methods}

\section{3. 1. ASAP-MS}

ASAP-MS with triple quadrupole analyzer (TQD, Acquility, Waters, USA) was used for the mass spectrometry analysis of CPS and CPO. The ASAP compartment consists of set probes and removable sample insertions, corona pin, and glass sample capillaries. The capillary glass tubes were sealed at the end and baked at $500^{\circ} \mathrm{C}$ to remove possible contaminations. The whole assembly $(100 \mathrm{~mm}$ in length) was inserted in the mass spectrometer. Positive ions were recorded between 50 and $700 \mathrm{Da}$. The ASAP probe with sample was inserted into the sealed source enclosure and desolvation gas was rapidly heated to $300{ }^{\circ} \mathrm{C}$. The heated nitrogen volatilizes the sample from a glass capillary tip, which is then ionized with a corona discharge pin, and MS spectrum is generated. The mass accuracy of the data was based on the instrument internal calibration.

Instrumental parameters were varied to avoid CPS and $\mathrm{CPO}$ fragmentation. Values accepted after optimization were: corona voltage $3.8 \mathrm{kV}$, extraction cone $2.0 \mathrm{~V}$, source temperature $150{ }^{\circ} \mathrm{C}$, desolvation gas flow $650 \mathrm{~L} \mathrm{~h}^{-1}$, sampling cone voltage $35 \mathrm{~V}$, desolvation temperature $300{ }^{\circ} \mathrm{C}$. Data were processed by the MassLynx software, version 4.1 .

\section{3. 2. GC-MS}

The GC-MS QP2010 Ultra instrument (Shimadzu, Kyoto, Japan) was used. A Rtx ${ }^{\oplus} 1$ (RESTEK, Crossbond ${ }^{\circ}$ $100 \%$ dimethylpolysiloxane, $30 \mathrm{~m} \times 0.25 \mathrm{~mm}$ I.D., $0.25 \mu \mathrm{m}$ film thickness) column was used. The injector temperature was $290^{\circ} \mathrm{C}$. The GC temperature program was held at 50 ${ }^{\circ} \mathrm{C}$ for $1 \mathrm{~min}$, then elevated to $140^{\circ} \mathrm{C}$ at rate of $20^{\circ} \mathrm{C} / \mathrm{min}$, and to $300^{\circ} \mathrm{C}$ at rate $10^{\circ} \mathrm{C} / \mathrm{min}$, with a hold time of $6 \mathrm{~min}$. Helium was used as the carrier gas at approximately 1.0 $\mathrm{mL} / \mathrm{min}$ pulsed in splitless mode. The mass spectrometric detector was operated in an electron impact ionization mode with an ionizing energy of $70 \mathrm{eV}$ and scanning range from 50 to $500 \mathrm{~m} / \mathrm{z}$.

All measurements have been done in triplicate. Quantification of CPS and CPO has been done by external calibration curves. The calibration ranges of CPS and CPO explored in this work were $0.2-5 \mathrm{mg} / \mathrm{L}$ and $0.3-3.0 \mathrm{mg} / \mathrm{L}$, respectively; linearity in the signal/concentration ratio was obtained also up to $30 \mathrm{mg} / \mathrm{L}$ for CPS and $25 \mathrm{mg} / \mathrm{L}$ for CPO. The correlation coefficient $R^{2}$ was higher than 0.99 . The limit of detection (LOD) for CPS was $0.08 \mathrm{mg} / \mathrm{L}$ and it was $0.1 \mathrm{mg} / \mathrm{L}$ for $\mathrm{CPO}$, calculated for samples injected three times. The limit of quantification (LOQ) was $0.2 \mathrm{mg} / \mathrm{L}$ for CPS and $0.3 \mathrm{mg} / \mathrm{L}$ for CPO. Relative standard deviations (RSD) were determined from ten measurements of a CPS standard solution $(C=2.5 \mathrm{mg} / \mathrm{L})$ and a $C P O$ standard solution $(C=1.5 \mathrm{mg} / \mathrm{L})$. The RSD was $4.1 \%$ for CPS and $4.8 \%$ for $\mathrm{CPO}$.

\section{3. 3. RP-UPLC-PDA}

Reversed-phase ultra high performance liquid chromatography (RP UPLC) was performed with an Acquility system with PDA detector (Waters, USA). Samples were injected automatically; the volume of injected sample was $10 \mu \mathrm{L}$. Acquity BEH Reverse Phase C18 $(1.7 \mu \mathrm{m} \times 100 \mathrm{~mm}$ $\times 2.1 \mathrm{~mm}$ ) column was used as a stationary phase for chromatographic separations. Mobile phases contained $0.1 \%$ formic acid in water $(v / v)(\mathrm{A})$ and $0.1 \%$ formic acid in acetonitrile $(v / v)(\mathrm{B})$. The following gradient elution conditions were used: $0-1.5 \min 45 \% \mathrm{~A} ; 1.5-2 \min 40 \% \mathrm{~B} ; 2-2.5$ $\min 20 \% \mathrm{~B} ; 2.5-4.5 \min 2 \% \mathrm{~B} ; 4.5-4.8 \min 55 \% \mathrm{~B} ; 4.8-6.0$ $\min 50 \% \mathrm{~B}$. Flow rate was set at $1 \mathrm{~mL} / \mathrm{min}$, and column temperature was $30^{\circ} \mathrm{C}$. The chosen absorption wavelengths were 230 and $280 \mathrm{~nm}$. Quantification of CPS and $\mathrm{CPO}$ has been done by external calibration curves. All measurements have been done in triplicate.

The calibration ranges of CPS and CPO were $0.1-5$ $\mathrm{mg} / \mathrm{L}$ and $0.03-2.5 \mathrm{mg} / \mathrm{L}$, respectively; linearity in the signal/concentration ratio was obtained also up to $30 \mathrm{mg} / \mathrm{L}$ for CPS and $20 \mathrm{mg} / \mathrm{L}$ for CPO. The correlation coefficient $R^{2}$ was higher than 0.99 . The LOD for CPS was $0.03 \mathrm{mg} / \mathrm{L}$ and it was $0.01 \mathrm{mg} / \mathrm{L}$ for $\mathrm{CPO}$, calculated for samples injected three times. The LOQ was $0.10 \mathrm{mg} / \mathrm{L}$ for CPS and $0.03 \mathrm{mg} / \mathrm{L}$ for CPO. The accuracy and precision were evaluated by means of the recovery: values obtained by 
post-extraction addition of standard to treated apples were $98-108 \%$ and $96-104 \%$ for the two compounds, respectively. RSD values were determined from ten measurements of CPS standard solution $(C=0.3 \mathrm{mg} / \mathrm{L})$ and CPO standard solution $(C=0.8 \mathrm{mg} / \mathrm{L})$. The RSD was $2.2 \%$ for CPS and $3.3 \%$ for $\mathrm{CPO}$.

\section{4. Gamma Irradiation Experiments}

Gamma irradiation experiments were carried out in the metrology dosimetry laboratory at the Institute of Nuclear Sciences (Belgrade). The radiation unit IRPIK-B was used as a functional generator with a source of gamma radiation Co-60. The measured value of the absorbed dose in the air at the reference point for the irradiation was $48.27 \mathrm{~Gy} / \mathrm{h}$. At the point at which samples were positioned, the absorbed dose in water was $53.51 \mathrm{~Gy} / \mathrm{h}$. After each individual campaign irradiation, the total value of the absorbed dose in each sample was 3.5-3.8 kGy, depending on time of irradiation. In general, the relation between the absorbed dose in air and absorbed dose in water as the material that is irradiated with gamma rays is:

$$
D_{W}=D_{a i r} \cdot \frac{\left(\frac{\mu}{\rho}\right)_{e n, a i r}}{\left(\frac{\mu}{\rho}\right)_{n n, W}}
$$

where $D_{\mathrm{W}}$ and $D_{\text {air }}$ are the absorbed dose in the water and absorbed dose in the air, respectively, and $\left(\frac{\mu}{\rho}\right)_{e, a, i}$ and $\left(\frac{\mu}{\rho}\right)_{e, t, W}$ are the energy absorption coefficients for air and water, respectively. It was assumed that absorption of irradiation in apple samples is equivalent to that in water.

\section{5. Sample Preparation}

The plant protection formulations based on CPS were applied to 20 samples of apples "Idared" bought in supermarkets, and to 20 samples of the same variety obtained from orchards. The supermarket samples were sprayed by $2 \mathrm{~mL}$ of EC formulation (dissolved in a water methanol mixture, 3:1, v/v) under $100 \mathrm{kPa}$ air pressure from a Potter precision laboratory spray tower (Burkard Scientific, UK). Spraying was performed under controlled conditions of temperature $\left(17^{\circ} \mathrm{C}\right)$ and relative humidity (45\%). The treated samples were collected in plastic bags after treatment and stored at $-18{ }^{\circ} \mathrm{C}$ until further analysis. Some apples were further treated with $30 \% \mathrm{H}_{2} \mathrm{O}_{2}$ solution to cause initial degradation of EC formulation to form CPO.

For ASAP-MS analysis, the samples were brought to room temperature. Apples were peeled, and their skin was cut into small pieces (about $1 \times 1 \mathrm{~cm}$ ), and the ASAP-MS probe was dipped into the apple pieces. The skin was weighted before and after dipping the ASAP-MS probe. The sample was then inserted into the ionization source chamber. No particular sample pretreatment was needed for the ASAP-MS analysis, and MS data for each sample were collected in few seconds.

For the chromatographic analysis, apples were homogenized (15 g in $30 \mathrm{~mL}$ acetone), vortexed and centrifuged for $10 \mathrm{~min}$ at $3500 \mathrm{rpm}$. The procedure was repeated three times, and acetone extract was collected. The remaining apple homogenate was further mixed with $20 \mathrm{~mL}$ of petrol ether and $10 \mathrm{~mL}$ of dichloromethane. After centrifugation, the upper organic layer was collected and added to acetone extract by this modified Luke procedure. ${ }^{18}$ Combined extracts were evaporated on a water bath at $42-62{ }^{\circ} \mathrm{C}$ and reconstituted with methanol for UPLC-PDA analysis or dichloromethane for GC-MS analysis. For some apples, the skin was separated from the mesoderm, and each sample was treated separately.

Three extraction techniques, other than the described Luke procedure, have been tested: liquid phase extraction followed by analytes separation in Oasis ${ }^{\circ}$ HLB cartridge, extraction with multiwall carbon nanotubes (MWCNT) and extraction with QuEChERS kit. For the liquid phase extraction, $5 \mathrm{~g}$ of apples have been homogenized and extracted with $20 \mathrm{~mL}$ of acetonitrile; 5 $\mathrm{mL}$ of extract were diluted to $100 \mathrm{~mL}$ with a 50:50 water/ methanol mixture, and eluted through the Oasis ${ }^{\oplus}$ HLB cartridge (previously conditioned with methanol). Eluted solutions were evaporated to dryness at $42-64{ }^{\circ} \mathrm{C}$, and reconstituted with methanol for UPLC-PDA analysis or dichloromethane for GC-MS analysis. For the extraction with MWCNT, $6 \mathrm{~mL}$ PTFE tubes (Strata) were filled with $0.035 \mathrm{~g}$ MWCNT, sample was added, and $\mathrm{pH}$ was then set at 6-7.5 to enhance the analyte extraction. Analytes were eluted with a methanol solution, and then samples were evaporated to dryness and reconstituted as described above for the liquid phase extraction. As regards the QuEChERS kit extraction, $15 \mathrm{~g}$ of homogenized sample were loaded into an empty $50 \mathrm{~mL}$ tube, and $15 \mathrm{~mL}$ of a $1 \% \mathrm{CH}_{3} \mathrm{COOH}$ in acetonitrile solution were added. The first QuEChERS mixture was then added. After centrifugation at $1500 \mathrm{rpm}$ for $5 \mathrm{~min}, 3 \mathrm{~mL}$ of supernatant solution were transferred into another tube containing the second QuEChERS mixture. After centrifugation at $3000 \mathrm{rpm}$ for $5 \mathrm{~min}, 100 \mu \mathrm{L}$ of the final extract were transferred into a vial and diluted with methanol.

The extraction efficiency $\eta$ (\%) was calculated for each method. The combined Luke (Dutch) procedure gave an efficiency of $94 \% \pm 8 \%$, which was the highest among all obtained efficiencies. For the liquid phase extraction it was $84 \% \pm 13 \%$, for the MWCNT it was $88 \% \pm$ $9 \%$, and for the QuEChERS kit it was $90 \% \pm 8 \%$. Therefore, the combined Luke (Dutch) procedure was chosen for apple preparation for the UPLC-PDA analyses. 


\section{Results and Discussion}

\section{1. ASAP-MS}

The interpretation of ASAP-MS spectra of CPS and $\mathrm{CPO}$ was performed in accordance to $m / z$ values and isotopic pattern. The protonated CPS is at $m / z 351.5 \pm 0.5 \mathrm{Da}$, and the protonated CPO is at $m / z 335.5 \pm 0.5 \mathrm{Da}$. The nontoxic metabolite TCP can also be observed at $\mathrm{m} / z 198$ with very low abundance. CPS and CPO are chlorinated compounds with three chlorine atoms which are excellently suitable for interpretation by isotope distribution. For example, the isotopic pattern for protonated CPS is 350:351:352:353:354:355:356, and calculated relative ion intensities are 97:11:100:11:36:4:5, respectively. In this pattern the even $\mathrm{m} / z$ values $(350,352 \ldots)$ stem mainly from the chlorine isotopes ${ }^{35} \mathrm{Cl}(75.8 \%$ natural abundance) and ${ }^{37} \mathrm{Cl}$ (24.2\% natural abundance), and the uneven values $(351,353 \ldots)$ from the carbon isotopes ${ }^{12} \mathrm{C}$ (98.9\% natural abundance) and ${ }^{13} \mathrm{C}(1.1 \%$ natural abundance). Theoretical ratio is in good agreement with ion ratio detected experimentally from standard and from apple samples (an example of experimental pattern is reported in Figure 1S in the Appendix A - Supporting Information), ${ }^{7,19}$

The ASAP-MS spectra of a blank apple and of an apple treated by $50 \mathrm{mg} / \mathrm{L} \mathrm{EC}$ formulation and with $\mathrm{H}_{2} \mathrm{O}_{2}$ are shown in Figure 2. If the two spectra are compared, the appearance of two new intense signals (10-fold more intense than other $\mathrm{m} / \mathrm{z}$ signals) due to CPS and CPO can be observed: CPS was added with the EC formulation, whereas $\mathrm{CPO}$ was produced by the $\mathrm{H}_{2} \mathrm{O}_{2}$ addition which simulates CPS degradation.
ASAP-MS might be used also for the detection of these additional compounds.

\section{2. Results of Chromatographic Analyses}

Chromatographic techniques (GC-MS and UPLC-PDA) were validated and applied for accurate measurements of $\mathrm{CPO}$ and $\mathrm{CPS}$ in apples, in order to acquire the "true" concentrations of these compounds.

The identity of CPS and CPO in GC-MS has been confirmed from the electron impact (EI) spectra which gave confirmatory product ions, as shown in the Supporting Information (Figures $2 S$ and $3 S$ ). The same ions are reported in Wiley database libraries. As well, the retention times of CPS and CPO were identical to those of the standard materials. The identification by UPLC-PDA techniques has been done by the retention time, which was identical to that of the standard material. The retention times were $4.23 \mathrm{~min}$ for CPS, $3.08 \mathrm{~min}$ for CPO, and $2.01 \mathrm{~min}$ for TCP.

From the validation data reported in the Experimental section, UPLC-PDA demonstrated to have slightly better analytical performances (LOD, LOQ, recovery) than GC-MS. For this reason, the subsequent quantitative analyses have been performed using UPLC-PDA. Some quantitative results obtained on apples (blank or treated with pesticide formulations) are shown in Table $1 \mathrm{~S}$ in the Supporting Information. These results show that CPS residues remained on apple skin, while apple mesoderm did not contain the pesticide. Untreated samples (domestic apple) were also CPS free.

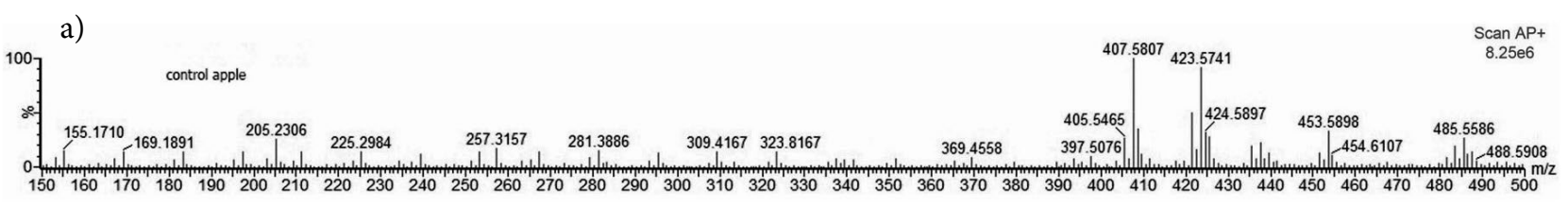

b)

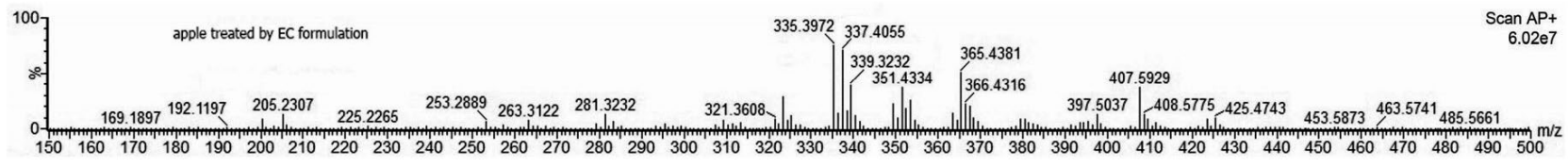

Figure 2. ASAP-MS spectra of a control apple (a) and of an apple treated with $50 \mathrm{mg} / \mathrm{L} \mathrm{EC}$ formulation and with $\mathrm{H}_{2} \mathrm{O}_{2}(\mathbf{b})$.

According to literature data, ${ }^{20-22}$ some additional compounds can be likely identified in Figure 2: naringenin pentose $(\mathrm{m} / \mathrm{z} 405), p$-coumaric pentose $(\mathrm{m} / z$ 326), phloridzin $(\mathrm{m} / \mathrm{z} 435)$, hyperoside (quercetin 3-O-galactoside) or isoquercetin $(\mathrm{m} / z 463)$, ferulic acid $(\mathrm{m} / z 368)$, cyanidin pentosine $(m / z 419)$, cyanidin hexoside $(\mathrm{m} / z$ 449), and quercetin pentoside $(\mathrm{m} / \mathrm{z} 435)$. In principle, therefore,

\section{3. Comparison Between ASAP-MS and Chromatographic Measurement of CPS and CPO in Apples}

The results obtained in the analysis of two samples for both CPS and CPO by using two different techniques, UPLC-PDA and ASAP-MS, are reported in Table 1. The first column reports the concentrations of EC or EW formulations used for apples spraying.

Although results obtained by ASAP-MS method were different than those obtained by UPLC-PDA meth- 
od, the order of magnitude of the values given by the two techniques was the same, and relative differences were not very large (around 10-20\%). Indeed, ASAP-MS results were obtained in few minutes, whereas UPLC-PDA values required a $10-100$-fold longer time. This indicated that ASAP-MS technique can represent a rapid and semiquantitative method for the analysis of CPS and CPO.
The quantitative results for the measure of the degradation efficiency were obtained with UPLC-PDA and are shown in Table 2. The last column reports the removal efficiency of CPS (if applicable also of CPO), as a function of the gamma irradiation doses reported in the previous column and/or of the $\mathrm{H}_{2} \mathrm{O}_{2}$ pretreatment.

The pretreatment with $\mathrm{H}_{2} \mathrm{O}_{2}$ caused only a limited

Table 1. Comparison between results from UPLC-PDA and from ASAP-MS in the analysis of two apple samples.

\begin{tabular}{lccc}
\hline sample & technique & CPS $[\mathbf{m g} / \mathbf{k g}]$ & CPO $[\mathbf{m g} / \mathbf{k g}]$ \\
\hline treated with 50 - EC & UPLC-PDA & $0.65 \pm 0.02$ & $0.06 \pm 0.01$ \\
treated with 50 - EC & ASAP-MS & $0.58 \pm 0.03$ & $0.05 \pm 0.01$ \\
treated with 50 - EW & UPLC-PDA & $0.60 \pm 0.03$ & $0.26 \pm 0.02$ \\
treated with 50 - EW & ASAP-MS & $0.54 \pm 0.02$ & $0.21 \pm 0.02$ \\
\hline
\end{tabular}

\section{4. Effect of Gamma Ray Treatment on the Removal of CPS and CPO from Treated Apples}

The GC-MS chromatogram (recorded as total ion chromatogram, TIC) obtained in EC formulations (5 $\mathrm{mg} / \mathrm{L}$ ) before gamma irradiation is presented in Figure $4 \mathrm{Sa}$ in the Supporting Information. The peak of CPS was observed at $t_{\mathrm{R}}=18.27 \mathrm{~min}$. Other minor formulation ingredients can be seen at different $t_{\mathrm{R}}$ values. When the analysis was repeated after gamma irradiation, the CPS peak almost disappeared (Figure 4Sb): CPS peak area is around $10-15 \%$ of the same peak in Figure 4Sa. Gamma irradiation caused the appearance of the CPO peak at $t_{\mathrm{R}}=18.03$ $\mathrm{min}$ and of TCP at $t_{\mathrm{R}}=12.77 \mathrm{~min}$. Both compounds were produced from the degradation of CPS.

Figure 3 shows the ASAP-MS spectra of a blank apple gamma irradiated (the same sample of Figure 2a), and of an apple treated with $50 \mathrm{mg} / \mathrm{L} \mathrm{EC}$ formulation, with $\mathrm{H}_{2} \mathrm{O}_{2}$ and then gamma irradiated (the same sample of Figure $2 b$ ). Both apples show an almost identical spectrum, indicating that the degradation was effective, and that the treated apple was almost identical to a blank (i.e. not polluted) apple. degradation of CPS (around 35-40\%), and it caused the production of large amounts of $\mathrm{CPO}$ due to chemical oxidation of CPS. The exposure to gamma rays caused the removal of CPS and of CPO depending on the irradiation dose and on the irradiation time. $2.5 \mathrm{kGy}$ for $66 \mathrm{~h}$ was not sufficient for pesticide removal, as the removal percentage was below $50 \%$. A good efficiency was achieved for a 3.5 $\mathrm{kGy}$ dose and for a $66 \mathrm{~h}$ treatment, as the removal percentage of CPS reached $90 \%$. The upper dose of $3.8 \mathrm{kGy}$ for 72 $\mathrm{h}$ gave even better results, but the increase with respect to $3.5 \mathrm{kGy}$ for $66 \mathrm{~h}$ was not very large. Little amounts of $\mathrm{CPO}$ appear as a degradation product of CPS after gamma irradiation. However, if CPO is present on apples in large amounts, it is degraded as well by gamma irradiation, as demonstrated in samples pretreated with $\mathrm{H}_{2} \mathrm{O}_{2}$. The parameters of gamma irradiation and their effects are in agreement with literature data for interaction of gamma irradiation with water medium. ${ }^{23-25}$

The removal efficiency of gamma irradiation can be easily checked also by ASAP-MS, by measuring the absolute intensities of the relevant pesticide peaks before and after irradiation. For example, with reference to Figures 2 and 3 , in apples treated with 50 - EC the average intensi-

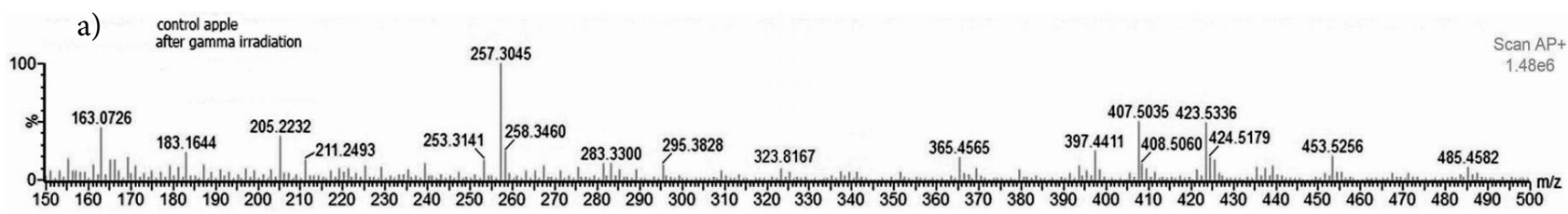

b)

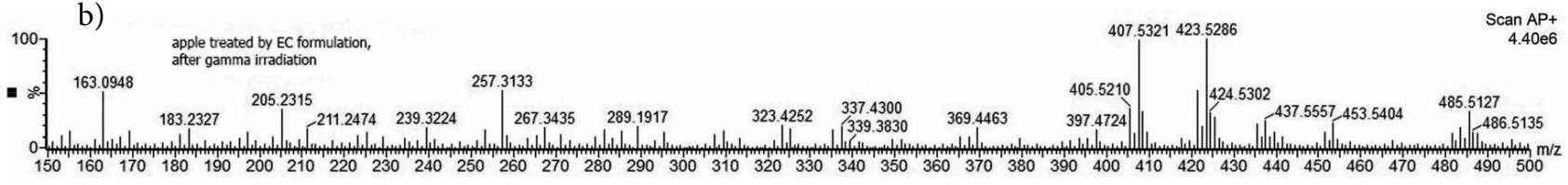

Figure 3. ASAP-MS spectra of a control apple after gamma irradiation (a) and of an apple treated with $50 \mathrm{mg} / \mathrm{L}$ EC formulation and with $\mathrm{H}_{2} \mathrm{O}_{2}$ and then gamma irradiated $(\mathbf{b})$. 
Table 2. Removal of CPS and CPO by gamma ray irradiation and, if used, by $\mathrm{H}_{2} \mathrm{O}_{2}$ pre-treatment. Values were determined by UPLC-PDA.

\begin{tabular}{|c|c|c|c|c|c|}
\hline sample & CPS $[\mathrm{mg} / \mathrm{kg}]$ & $\mathrm{CPO}[\mathrm{mg} / \mathrm{kg}]$ & $\mathrm{H}_{2} \mathrm{O}_{2}$ pretr. & $\begin{array}{c}\text { Gamma irrad. doses } \\
{[\mathrm{kGy}] / \text { time }[\mathrm{h}]}\end{array}$ & $\begin{array}{c}\text { Removal of CPS or } \\
\text { CPS/CPO [\%] }\end{array}$ \\
\hline Blank apple & $\leq 0.03$ & $\leq 0.03$ & no & - & - \\
\hline treated with $5-\mathrm{EC}$ & $4.93 \pm 0.07$ & - & no & - & - \\
\hline treated with 5 - EC & $2.76 \pm 0.04$ & $0.14 \pm 0.02$ & no & $2.5 / 66$ & 44 \\
\hline treated with 5 - EC & $0.55 \pm 0.02$ & $0.03 \pm 0.01$ & no & $3.5 / 66$ & 89 \\
\hline treated with $5-\mathrm{EC}$ & $0.56 \pm 0.02$ & $0.03 \pm 0.01$ & no & $3.8 / 72$ & 88 \\
\hline treated with $5-\mathrm{EW}$ & $4.96 \pm 0.05$ & - & no & - & - \\
\hline treated with $5-\mathrm{EW}$ & $2.72 \pm 0.07$ & $0.13 \pm 0.01$ & no & $2.5 / 66$ & 45 \\
\hline treated with 5 - EW & $0.54 \pm 0.02$ & $0.03 \pm 0.01$ & no & $3.8 / 72$ & 89 \\
\hline treated with $50-\mathrm{EC}$ & $47.2 \pm 1.0$ & - & no & - & - \\
\hline treated with $50-\mathrm{EC}$ & $2.7 \pm 0.1$ & $0.18 \pm 0.02$ & no & $3.8 / 72$ & 94 \\
\hline treated with $50-$ EC & $30.2 \pm 1.0$ & $14.10 \pm 0.08$ & yes & - & 36 \\
\hline treated with $50-\mathrm{EC}$ & $0.65 \pm 0.02$ & $0.06 \pm 0.01$ & yes & $3.8 / 72$ & $98 \mathrm{CPS} / 99 \mathrm{CPO}$ \\
\hline treated with $50-\mathrm{EW}$ & $48.2 \pm 1.1$ & - & no & - & - \\
\hline treated with $50-\mathrm{EW}$ & $2.6 \pm 0.1$ & $0.16 \pm 0.02$ & no & $3.8 / 72$ & 94 \\
\hline treated with $50-\mathrm{EW}$ & $29.2 \pm 1.1$ & $16.2 \pm 0.1$ & yes & - & 39 \\
\hline treated with $50-\mathrm{EW}$ & $0.60 \pm 0.03$ & $0.26 \pm 0.02$ & yes & $3.8 / 72$ & $98 \mathrm{CPS} / 98 \mathrm{CPO}$ \\
\hline
\end{tabular}

ties of the protonated CPS ion, $m / z=351$, before irradiation were $373 \cdot 10^{7}$. The intensities of the same ion after gamma irradiation were $4.4 \cdot 10^{7}$. The efficiency of CPS removal can be thus calculated to be $99 \%$, in very good agreement with the value (98\%) determined by UPLC-PDA. Also, the average intensities of the protonated CPO ion at $m / z=335$ was $259 \cdot 10^{7}$ before irradiation and $3.5 \cdot 10^{7}$ after irradiation, so that the effect of removal of CPO was $99 \%$, identical to what was found by UPLC-PDA. ASAP-MS can therefore represent a rapid tool to accurately check CPS and CPO removal from apples.

\section{Conclusions}

ASAP-MS was optimized for the determination (identification and semiquantification) of CPS and CPO in raw apples. The technique is simple, rapid and economical, as it enables the analysis without purification and preparation steps. Results are indeed not very accurate if compared with those of validated chromatographic techniques (bias was 10-20\%), thus indicating that ASAP-MS represents a semiquantitative tool, but these values can be obtained much more rapidly than with validated chromatographic methods.

In the frame of checking possible degradation treatments of CPS and CPO in apples, gamma irradiation demonstrated to be effective enough with a $3.5 \mathrm{kGy}$ dose for a $66 \mathrm{~h}$ treatment. ASAP-MS gave in this case accurate degradation percentages by simply measuring the absolute percentages detected for the CPS and CPO ions before and after irradiation. Degradation percentages obtained from ASAP-MS were in very good agreement with the ones obtained by chromatography. This indicates that ASAP-MS can be very well suitable to rapidly and easily check CPS and CPO removal from apples.

\section{Acknowledgements}

This work was supported by the Ministry for Science of the Republic of Serbia Grant No. (OI 172019, III 45014, OI 175039, OI 172023 and OI 172016).

Appendix A: Supporting Information

\section{References}

1. S. Gašić, D. Brkić, A. Tomašević, Pestic. Phytomed. 2011, 26, 409-413. DOI:10.2298/PIF1104409G

2. X. Dai, F. Fan, Y. Ye, F. Chen, Z. Wu, X. Lu, Q. Wei, J. Chen, Y. Yan, L. Liao, J. Forensic Sci. Med. 2017, 3, 22-25.

DOI:10.4103/jfsm.jfsm_2_17

3. H. Molet, A. Grubeman, Formulation Technology, $2^{\text {nd }}$ ed. Wiley-VCH, Weinheim, Germany 2001, pp. 389-397.

4. E. Hodgson, A Textbook of Modern Toxicology, $3^{\text {rd }}$ ed, John Wiley \& Sons Inc., United States, 2004, pp. 56-64.

DOI:10.1002/0471646776

5. D. Tsipi, H. Botitsi, A. Economou, Mass Spectrometry for the Analysis of Pesticide Residues and Their Metabolites, Wiley, USA. 2015, pp. 187-205, 207-229.

DOI:10.1002/9781119070771

6. Y. Latif, S. T. H. Sherazi, M. I. Bhanger, S. Nizamani, Am. J. Analyt. Chem. 2012, 3, 587-595.

DOI:10.4236/ajac.2012.38077

7. K. Choi, H. Joo, R. L. Rose, E. Hodgson, J. Biochem. Mol. Toxicol. 2006, 20, 279-291. DOI:10.1002/jbt.20145

8. J. Choi, E. Hodgson E, R. L. Rose, Drug Metab. Drug Interact. 2004, 20, 233-245.

9. T. Suriyo, P. Tachachartvanich, D. Visitnonthachai, P. Watcharasit, J. Satayavivad, Toxicol. 2015, 2, 117-129.

DOI:10.1016/j.tox.2015.10.009

10. R. L. Rose, J. Tang, J. Choi, Y. Cao, A. Usmani, N. Cherring- 
ton, E. Hodgson, Scand J. Work Environ. Health. 2005, 31, 156-163.

11. J. Hajšlova, J. Zrostlıkova, J. Chromatogr. A. 2003, 1000, 181197. DOI:10.1016/S0021-9673(03)00539-9

12. Europen Norme, BS EN 15662: 2008, Foods of plant origin: determination of pesticide residues using GC-MS and/or LCMS/MS following acetonitrile extraction/partitioning and clean up by dispersive SPE - QuEChERS method.

13. S. Chandra, A. N. Mahindrakar, L. P. Shinde, Int. J. ChemTech Res. 2014, 6, 124-130.

14. N. George, P.S. Chauhan, S. Sondhi, S. Saini, N. Puri, N. Gupta, Int. J. Pure Appl. Sci. Technol. 2014, 20, 79-94.

15. X. Liu , B. Mitrevski, D. Li, J. Li, P. J. Marriott, Microchem. J. 2013, 111, 25-31. DOI:10.1016/j.microc.2012.07.013

16. M. Khanmohammadi, M. A. Karimi, K. Ghasemi, M. Jabbari, A. B. Garmarudi, Talanta 2007, 72, 620-625. DOI:10.1016/j.talanta.2006.11.029

17. C. N. McEwen, R. G. McKay, B. S. Larsen, Anal. Chem. 2005, 77, 7826-7831. DOI:10.1021/ac051470k

18. M. Cvijović, S. Stanković, B.Tanović in: G. Ristic (ed) $4^{\text {th }}$ Intern. Confer. On Radiation and Application in Various Fields of Research. Niš, Serbia, 2016, pp. 452.
19. S. J. Lenothay, A. de Kok, M. Hiemstra, P. van Bodegraven, J. AOAC Int. 2005, 88, 595-614.

20. Scientific Instrument Services [http://www.sisweb.com/ mstools/isotope.htm].

21. L. M. Bystrom, B. A. Lewis, D. L. Brown, E. Rodriguez, R. L. Obendorf, Food Chem. 2008, 111, 1017-1024.

DOI:10.1016/j.foodchem.2008.04.058

22. F. Sanchez-Rabaneda, O. Jauregui, R. M. Lamuela-Raventos, F. Viladomat, J. Bastida, C. Codina, Rapid Commun. Mass Spectrom. 2004, 18, 553-563. DOI:10.1002/rcm.1370

23. A. Balasz, M. Toth, B. Balzics, E. Hethelyi, S. Szarka, E. Fiscor, G. Fizcek, E. Lembercovich, A. Blazovich, Fitoterapia. 2012, 83, 1356-1363. DOI:10.1016/j.fitote.2012.04.017

24. M. N. Mori, H. Oikawa, M. H. O. Sampa, C. L. Duarte, J. Radioanal. Nucl. Chem. 2006, 270, 99-102. DOI:10.1007/s10967-006-0314-3

25. M. S. Hossain, A. N. M. Fakhruddin, M. A. Z. Chowdhury, M. K. Alam, J. Environ. Chem. Eng. 2013, 1, 270-274. DOI:10.1016/j.jece.2013.05.006

\section{Povzetek}

Klorpirifos (CPS) je strupen pesticid, ki se nahaja v številnih fitofarmacevtskih sredstvih in se pod naravnimi pogoji le malo razgrajuje. Razkroj vodi do nastanka strupenega metabolita klorpirifos-oksona (CPO). Analizne tehnike za določevanje CPS in CPO, kot sta UPLC-PDA in GC-MS, so točne, vendar tudi drage in časovno zamudne ter potrebujejo predpripravo vzorca. Z namenom najti hitrejši in bolj preprost analizni postopek smo za določitev CPS in CPO v jabolkih (Malus domestica „Idared”) optimizirali sondo za trdne vzorce pri atmosferskem tlaku v povezavi z masno spektrometrijo (ASAP-MS). Identifikacijo analitov smo izvedli na osnovi protoniranega iona in izotopskega vzorca, medtem ko je bila kvantifikacija osnovana na intenziteti vrhov. Dobljene rezultate smo potrdili z revalidiranima UPLC-PDA in GC-MS metodama. Koncentracije CPS in CPO, določene z ASAP-MS in UPLC-PDA, so se nekoliko razlikovale (v povprečju za 10-20\%), kar je pokazalo, da je ASAP-MS lahko semikvantitativno orodje za kvantifikacijo teh spojin. Dodaten namen te raziskave je bil preizkusiti učinkovitost gama ožarčenja za odstranjevanje CPS in CPO iz jabolk, zato smo jih analizirali pred in po ožarčenju: 89-99\% CPS in CPO se je razgradilo pri dozah 3,5-3,8 kGy in času ožarčenja 66-72 h na vzorec. Z UPLC-PDA in ASAP-MS smo dobili identične rezultate razgradnje, kar pomeni, da je slednja tehnika zelo primerna za hitro preverjanje razgradnje pesticidov v jabolkih. 